\title{
Synthesis of bimodally porous titania powders by hydrolysis of titanium tetraisopropoxide
}

\author{
Ki Chang Song ${ }^{\text {a) }}$ and Sotiris E. Pratsinis ${ }^{\text {b) }}$ \\ Institute of Process Engineering, Swiss Federal Institute of Technology, ETH-Zentrum, CH-8092 \\ Zurich, Switzerland
}

(Received 1 December 1999; accepted 24 July 2000)

\begin{abstract}
Bimodally porous titania powders with controlled phase composition and porosity were made by hydrolysis of titanium tetraisopropoxide (TTIP) and calcination. The extent of calcination was followed by thermogravimetric differential thermal analysis and Fourier transform infrared spectroscopy. The specific surface area (SSA) of the powders ranged from 10 to $500 \mathrm{~m}^{2} / \mathrm{g}$ as determined by nitrogen adsorption. The SSA increased by decreasing either the water concentration during hydrolysis or the calcination temperature. The pore size distribution was bimodal with fine intraparticle pore diameters at $1-6 \mathrm{~nm}$ and larger interparticle pore diameters at $30-120 \mathrm{~nm}$ as determined by nitrogen adsorption isotherms. The particle phase composition as determined by x-ray diffraction ranged from amorphous to crystalline anatase and rutile largely proportional to the calcination temperature and to a lesser extent on the initial $\mathrm{H}_{2} \mathrm{O}$ /TTIP molar ratio.
\end{abstract}

\section{INTRODUCTION}

Titania powders are widely used as a white pigment, an adsorbent, and a major component in many electronic devices (e.g. capacitors and varistors) and have recently become of interest as functional materials such as a photosemiconductor and a photocatalyst. ${ }^{1-5}$ The most common procedures of preparing the titania powders have been based on the hydrolysis of acidic solutions of Ti(IV) salts ${ }^{6,7}$ or by gas-phase oxidation reaction of $\mathrm{TiCl}_{4}$ at high temperatures. ${ }^{3,8}$ Recently, however, methods of vapor-phase hydrolysis, ${ }^{9}$ pyrolysis, ${ }^{10}$ and sol-gel synthesis $^{2,11}$ of organic precursors (e.g., titanium tetraisopropoxide, TTIP) have been developed to synthesize titania nanoparticles with high purity.

Sol-gel synthesis provides a way to make nanoparticles by a chemical reaction in solution starting with metal alkoxides as a precursor. An advantage of the solgel synthesis is that it is possible to obtain large amounts of powder with a high level of chemical purity. ${ }^{12}$ In this sol-gel synthesis two simultaneous reactions-hydrolysis and polycondensation - take place when TTIP reacts with water. ${ }^{13}$ These two reactions are sensitive to water concentration, $\mathrm{pH}$, type and amount of solvent, reaction temperature, and mixing conditions. Among the reaction

\footnotetext{
a) On leave from Konyang University, Nonsan, South Korea.

b) Address all correspondence to this author.

e-mail: pratsinis@ivuk.mavt.ethz.ch
}

variables, especially the water concentration significantly influences the properties of the titania powders as TTIP reacts quickly with water.

Ding et al. ${ }^{15}$ synthesized titania powders from titanium tetrabutoxide (TTB) by controlling the water concentration during hydrolysis. They reported that the grain size of powders prepared at low $\mathrm{H}_{2} \mathrm{O} / \mathrm{TTB}$ molar ratios was smaller than that of powders made at high molar ratios. As a result, the anatase to rutile phase transformation temperature for powders made at low $\mathrm{H}_{2} \mathrm{O} / \mathrm{TTB}$ molar ratios was less than that of powders at high $\mathrm{H}_{2} \mathrm{O}$ / TTB ratios. Sasamoto et al. ${ }^{16}$ also prepared titania powders from TTIP by controlling the initial water concentration. However, they found that the water concentration had no effect on the anatase to rutile transformation temperature. In contrast, Kato ${ }^{17}$ reported that anatase to rutile transformation rate and the specific surface area of titania powders increased with increasing $\mathrm{H}_{2} \mathrm{O}$ /TTIP molar ratios.

Recently, preparation of porous powders with controlled pore size and high surface area for uses such as filters, adsorbates, catalysts, and catalyst supports ${ }^{18}$ has attracted much interest. The sol-gel synthesis is a very effective method to control pore sizes of inorganic oxide powders. ${ }^{19}$ Although many research groups have explored the characteristics of titania powders prepared by controlling the water concentration during the hydrolysis reaction, to the best of our knowledge, none has examined the influence of water concentration and calcination temperature on the titania pore characteristics. This paper 
describes the effect of initial water concentration and calcination temperature on the characteristics of product porous titania powders by thermogravimetric differential thermal analysis, Fourier transform infrared spectroscopy (FTIRS), nitrogen adsorption, and x-ray diffraction (XRD).

\section{EXPERIMENTAL}

\section{A. Sample preparation}

Titanium tetraisopropoxide [TTIP; $\mathrm{Ti}\left(\mathrm{OC}_{3} \mathrm{H}_{7}\right)_{4}, 97 \%$ ] supplied by Aldrich was used as a precursor. To moderate the high reactivity of TTIP with water, the TTIP was first dissolved in anhydrous ethyl alcohol at a molar ratio of $\mathrm{C}_{2} \mathrm{H}_{5} \mathrm{OH} / \mathrm{TTIP}=5$. Hydrolysis was carried out at room temperature by adding controlled amounts of distilled water slowly to the mixed solution (ethyl alcohol and TTIP) with a vigorous stirring for $1 \mathrm{~h}$. Powders were prepared at molar ratios of $\mathrm{H}_{2} \mathrm{O}$ to TTIP of 5, 20, 200, and 1000 and were labeled as R5, R20, R200, and R1000, respectively. On addition of the water into the mixed solution, a slurry containing white titanium hydroxide precipitate was formed. Clear liquid was removed from the flurry by filtering through a filter paper (MN 615, Macherey-Nagel, Düren, Germany) with openings less than or equal to $2-3 \mu \mathrm{m}$ in diameter. ${ }^{20}$ The filtered powder was dried at $150{ }^{\circ} \mathrm{C}$ for $24 \mathrm{~h}$, followed by calcination at different temperatures ranging from 300 to $800{ }^{\circ} \mathrm{C}$ for $1 \mathrm{~h}$ at a heating rate of $10^{\circ} \mathrm{C} / \mathrm{min}$.

\section{B. Characterization}

The powders were analyzed by thermogravimetric differential thermal analysis (TG-DTA; STA501, Bahr) at a heating rate of $10{ }^{\circ} \mathrm{C} / \mathrm{min}$ in flowing air. The infrared (IR) spectra of the powders were measured in the range from 500 to $4000 \mathrm{~cm}^{-1}$, using FTIRS (IFS 66v, Bruker, Karlsruhe, Germany). An x-ray diffractometer (D5000, Siemens, Karlsruhe, Germany) was used for identification of crystalline species in the calcined powders with $\mathrm{Ni}$-filtered $\mathrm{Cu} \mathrm{K}_{\alpha}$ radiation as the $\mathrm{X}$-ray source for diffraction angles $2 \theta$ between 20 and $60^{\circ}$. The weight fraction of rutile or anatase in the titania powders was calculated by ${ }^{21}$

$$
X=1 /\left(1+0.8 I_{\mathrm{A}} / I_{\mathrm{R}}\right),
$$

where $X$ is the weight fraction of rutile in the powders, while $I_{\mathrm{A}}$ and $I_{\mathrm{R}}$ are the X-ray integrated intensities of the (101) reflection of anatase and the (110) reflection of rutile. The crystallite sizes $\left(D_{h k l}\right)$ were calculated using Scherrer's equation: ${ }^{22}$

$$
D_{h k l}=K \lambda /\left(B_{h k l} \cos \theta\right),
$$

where $\lambda$ is the wavelength and $B_{h k l}$ is the full width at half maximum, while $K$ is a constant, $K=1.4$. The specific surface area (SSA) of the powders was analyzed by nitrogen adsorption in a Brunauer-Emmett-Teller analysis (BET) surface area analyzer (ASAP2010, Micromeritics, Norcross, GA). All powders were degassed at $150{ }^{\circ} \mathrm{C}$ prior to actual measurement. The SSA was determined by the multipoint BET method using the adsorption data in the relative pressure $\left(P / P_{0}\right)$ range $0.05-0.25$. The desorption isotherm was used to determine the pore size distribution using the Barrett, Joyner, and Halender (BJH) method with cylindrical pore size. ${ }^{23}$

\section{RESULTS AND DISCUSSION}

\section{A. Thermal Analysis}

Figure 1 shows the themogravimetric (TG) curves for the R5, R20, R200, and R1000 powders dried at $150{ }^{\circ} \mathrm{C}$. For the R5 and R20 powders, two main zones in weight loss are identified. The first zone from 50 to $250{ }^{\circ} \mathrm{C}$ corresponds to the removal of physically adsorbed water and alcohol. ${ }^{24}$ The second zone from 250 to $380{ }^{\circ} \mathrm{C}$ corresponds to the oxidation of residual organic components and removal of chemically adsorbed water. ${ }^{24}$ However, for the R200 and R1000 powders, only the first zone is observed, which corresponds to the removal of physically adsorbed water and alcohol.

Figure 2 shows the differential thermal analysis (DTA) corresponding to Fig. 1. For the R5 and R20 powders that were prepared at low water concentrations, an intensive exothermic peak is observed at $260{ }^{\circ} \mathrm{C}$, which is associated with the elimination and burning of organic components. On the other hand, for the R200 and R1000 powders prepared at high water concentrations, no exothermic peak is observed at $260{ }^{\circ} \mathrm{C}$. This indicates that the R5 and $\mathrm{R} 20$ powders contain more residual organic components

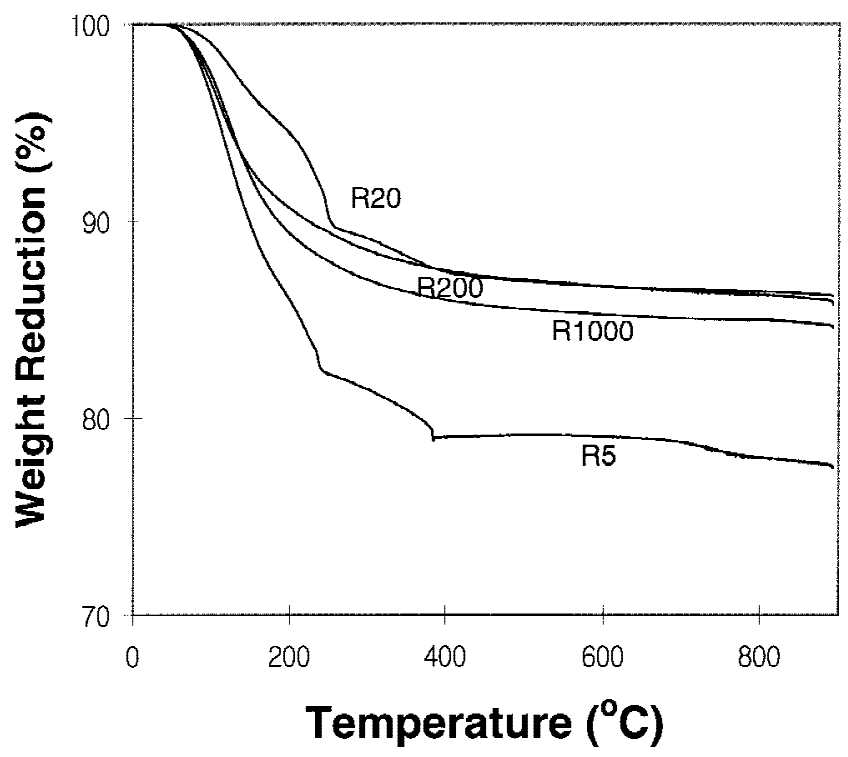

FIG. 1. Weight reduction of sol-gel made titania powders by TG analysis in flowing air. The powders were made at $\mathrm{H}_{2} \mathrm{O}$ /TTIP molar ratios of $5,20,200$, and 1000 and dried at $150{ }^{\circ} \mathrm{C}$. 
than the R200 and R1000 powders possibly due to incomplete hydrolysis. For the R5 powder, another exothermic peak at $390{ }^{\circ} \mathrm{C}$ is observed, corresponding to crystallization $^{24}$ of amorphous to anatase phase. However, the exothermic peak is not observed for the R20, R200, and R1000 powders that have already had anatase phase before $390{ }^{\circ} \mathrm{C}$ which will be shown in the XRD patterns of Figs. 5(b)-5(d).

Figure 3 shows IR spectra of the R5 powder heattreated at increasing temperatures. The peaks around 3410 and $1640 \mathrm{~cm}^{-1}$ correspond to the $\mathrm{OH}$ stretching and

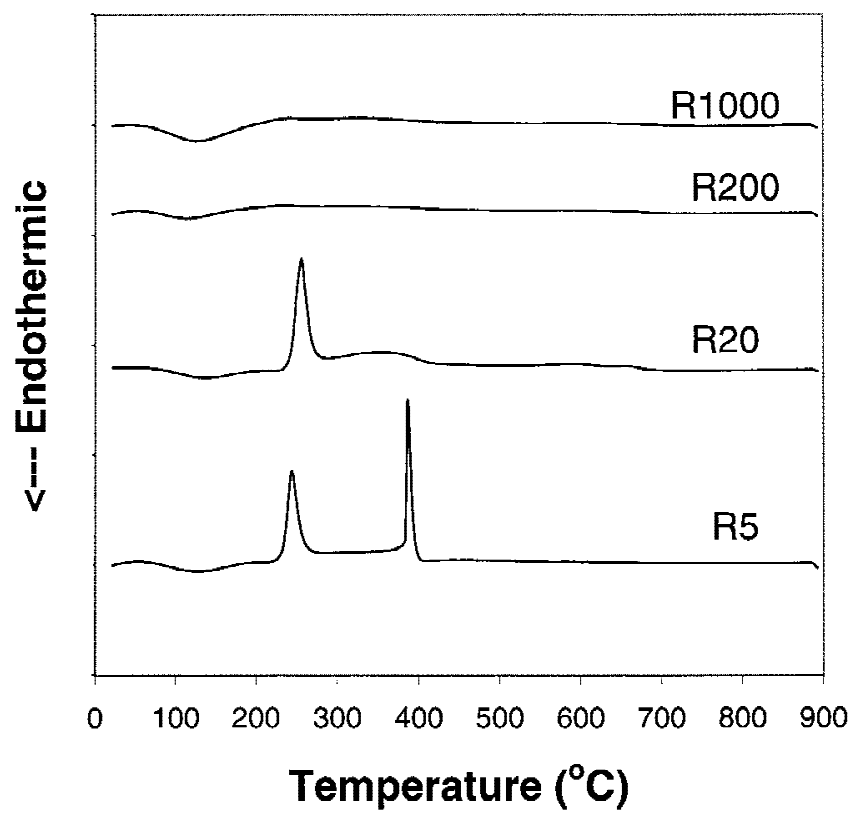

FIG. 2. DTA curves of sol-gel made titania powders. The powders were made at $\mathrm{H}_{2} \mathrm{O}$ /TTIP molar ratios of 5, 20, 200, and 1000 and dried at $150{ }^{\circ} \mathrm{C}$.

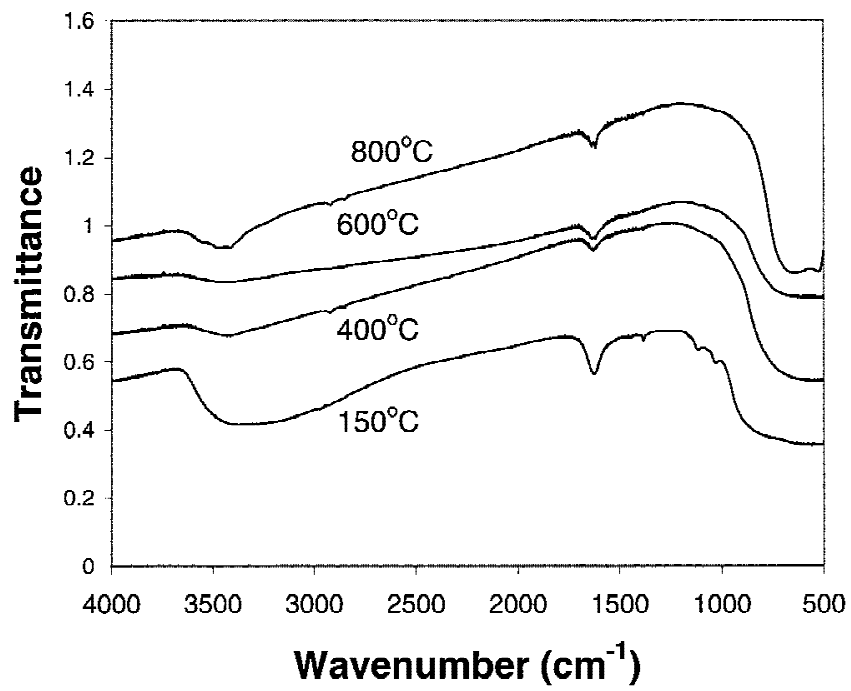

FIG. 3. FTIR spectra of the R5 powder at various calcination temperatures. bending, ${ }^{25}$ respectively. The intensity of these absorption bands decreases with increasing calcination temperature. The peak at $3172 \mathrm{~cm}^{-1}$ for the powder dried at $150{ }^{\circ} \mathrm{C}$ is attributed to the hydroxyl group ( $\equiv \mathrm{Ti}-\mathrm{OH}) .{ }^{26}$ This indicates that this powder consists of amorphous titanium hydroxide. This peak does not exist for the powder calcined at $400{ }^{\circ} \mathrm{C}$ due to the formation of crystalline anatase which will be shown in the XRD pattern of Fig. 5(a). Weaker peaks are also observed at 1440 and $1355 \mathrm{~cm}^{-1}$ and at 1160 and $1063 \mathrm{~cm}^{-1}$, which are associated with the bending of $\mathrm{C}-\mathrm{H}$ bonds and $\mathrm{C}-\mathrm{O}$ stretching in TTIP, respectively. ${ }^{25}$ This spectrum indicates that a significant amount of organic components remains in the R5 powder. However, the organic peaks disappear in the spectrum for $400{ }^{\circ} \mathrm{C}$ and this is ascribed to the oxidation of organic components, as confirmed by DTA in Fig. 2. Further heating to $800{ }^{\circ} \mathrm{C}$ gives rise to peaks at 695 and $525 \mathrm{~cm}^{-1}$, attributed to rutile. ${ }^{27}$ This is in agreement with the XRD pattern in Fig. 5(a).

Figure 4 shows the IR spectra of the powders made at different initial $\mathrm{H}_{2} \mathrm{O}$ /TTIP molar ratios and dried at $150{ }^{\circ} \mathrm{C}$. The R5 and R20 powders show the peak at $3172 \mathrm{~cm}^{-1}$ corresponding to the hydroxyl group, while the R200 and R1000 powders do not show it. This is attributed to the different phase composition of the powders dried at $150{ }^{\circ} \mathrm{C}$ : the R5 and R20 powders show amorphous titanium hydroxide [see Figs. 5(a) and 5(b)], while the R200 and R1000 powders exhibit anatase phase [see Figs. 5(c) and 5(d)].

\section{B. Phase composition}

Figures 5(a)-5(d) show the XRD patterns of the R5, R20, R200, and R1000 powders, respectively, at various calcination temperatures. The R5 and R20 powders dried

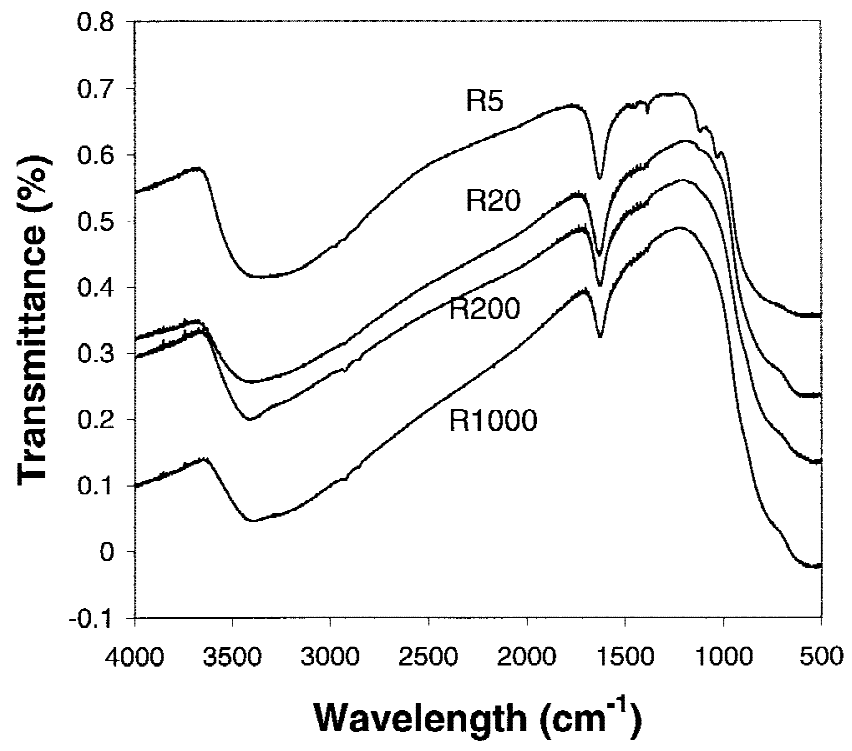

FIG. 4. FTIR spectra of the powders made at different initial $\mathrm{H}_{2} \mathrm{O}$ / TTIP molar ratios and dried at $150{ }^{\circ} \mathrm{C}$. 


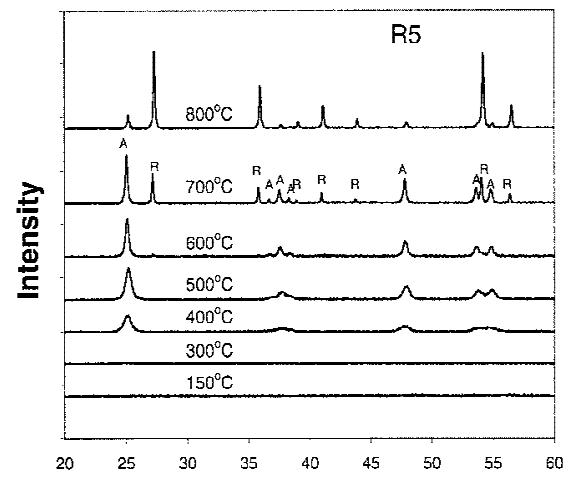

(a)

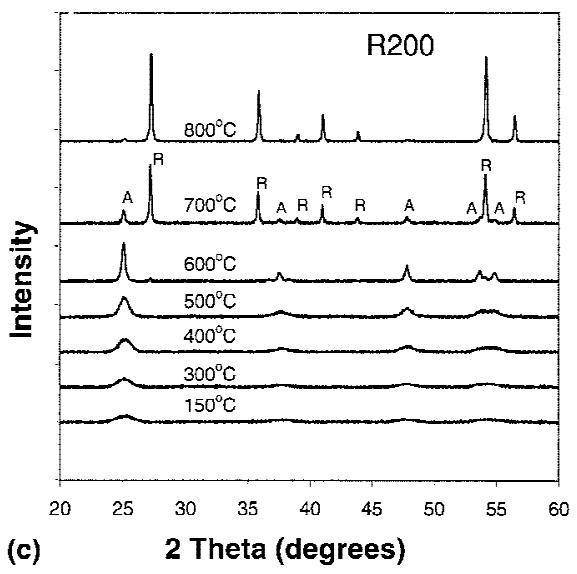

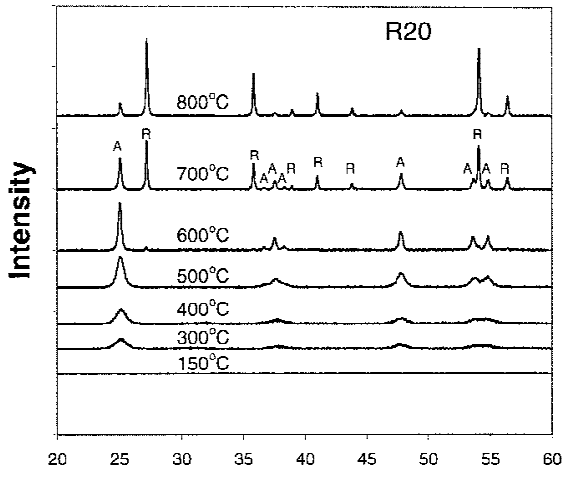

(b)

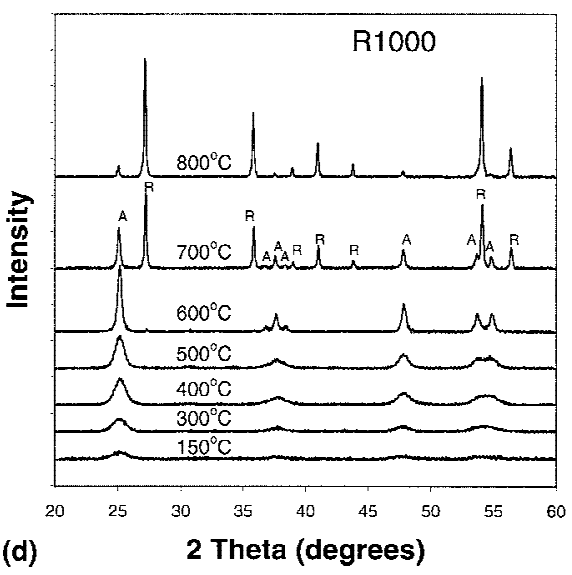

FIG. 5. XRD patterns of sol-gel made titania powders calcined at various temperatures. The powders were made at $\mathrm{H}_{2} \mathrm{O} / \mathrm{TTIP}$ molar ratios of (a) 5, (b) 20, (c) 200, and (d) 1000. The peaks marked A and R represent the anatase and rutile phases, respectively.

at $150{ }^{\circ} \mathrm{C}$ show an amorphous phase, while the R200 and R1000 powders exhibit an anatase phase. According to Terabe et al., ${ }^{28}$ when the water concentration during hydrolysis reaction was small, large amounts of unhydrolyzed alkyls remained in the powder. These alkyls prevent crystallization to anatase so that powders were amorphous. On the other hand, when the initial water concentration was large, the amount of residual alkyls preventing crystallization to anatase was small, so the molecular structure of the powder resembled that of the anatase phase which is more stable than the amorphous phase. ${ }^{28}$

It is also seen in Figs. 5(a) and 5(b) that the transformation of amorphous to anatase phase occurs at 400 and $300{ }^{\circ} \mathrm{C}$ for the R5 and R20 powders, respectively. However, in Figs. 5(c) and 5(d), pure anatase has already appeared at $150{ }^{\circ} \mathrm{C}$ for the R200 and R1000 powders and is maintained until $500{ }^{\circ} \mathrm{C}$. It is apparent that the phase transformation temperature from amorphous to anatase depends on the initial $\mathrm{H}_{2} \mathrm{O}$ /TTIP molar ratio. This is in agreement with the DTA analysis in Fig. 2. However, the phase transformation from anatase to rutile begins to appear at $600{ }^{\circ} \mathrm{C}$ for all powders, regardless of the initial $\mathrm{H}_{2} \mathrm{O} / \mathrm{TTIP}$ molar ratio.
At $700{ }^{\circ} \mathrm{C}$, there is a major change in phase structure depending on the initial $\mathrm{H}_{2} \mathrm{O}$ /TTIP molar ratio for all powders. With increasing initial $\mathrm{H}_{2} \mathrm{O}$ /TTIP ratio from 5 to 200 , the intensities of rutile peaks corresponding to the planes (110), (101), and (211) $\left(2 \theta=27.5^{\circ}, 36.2^{\circ}\right.$, and $54.4^{\circ}$, respectively) are bigger, while those of the anatase peaks corresponding to the planes (101), (004), and (200) $\left(2 \theta=25.3^{\circ}, 37.8^{\circ}\right.$, and $48.1^{\circ}$, respectively $)$ are smaller. This result indicates an enhancement of phase transformation from anatase to rutile with increasing initial $\mathrm{H}_{2} \mathrm{O}$ / TTIP molar ratio. It is interesting to note that the intensities of the rutile peaks in the R1000 powder are smaller than those in the R200 powder, while the intensities of the anatase peaks in the R1000 powder are bigger than those in the R200 powder, in spite of the increase of the initial $\mathrm{H}_{2} \mathrm{O}$ /TTIP molar ratio.

Figure 6 shows the calculated rutile weight fraction in the R5, R20, R200, and R1000 powders calcined at several temperatures for $1 \mathrm{~h}$. The rutile weight fraction increases with the increase of temperature from 600 to $800{ }^{\circ} \mathrm{C}$ for all powders. This fraction first shows an initial increase with increasing the initial $\mathrm{H}_{2} \mathrm{O}$ /TTIP molar ratio from 5 to 200 and then exhibits a decrease for the R1000 powder at a constant calcination temperature. 


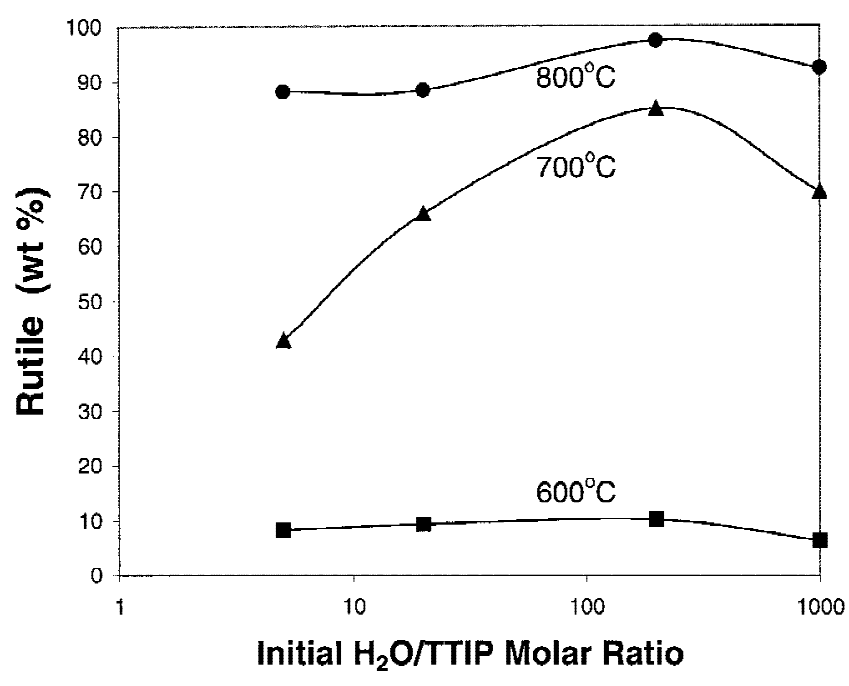

FIG. 6. Calculated rutile weight fractions of the powders made at different initial $\mathrm{H}_{2} \mathrm{O} / \mathrm{TTIP}$ molar ratios and calcined at several temperatures for $1 \mathrm{~h}$.

This means that the anatase to rutile transformation rate increases with increasing initial $\mathrm{H}_{2} \mathrm{O}$ /TTIP molar ratio for the powders made at low water concentrations, but that increase has a limit for the powders made at high water concentrations. This is in disagreement with Ding et al., ${ }^{15}$ who found the inhibition of the phase transformation of anatase to rutile with the increase of water concentration during the hydrolysis reaction. They carried out, however, the experiment under much smaller water concentrations (i.e., the initial $\mathrm{H}_{2} \mathrm{O}$ /TTIP molar ratios $=1,2,3,4)$ compared to this study. Our result is also in disagreement with Kato, ${ }^{17}$ who reported that the transformation rate of anatase to rutile increased with increasing water concentration in the range of initial $\mathrm{H}_{2} \mathrm{O}$ /TTIP molar ratios of 20-1000. They investigated, however, the transformation rate on the powders calcined at $900{ }^{\circ} \mathrm{C}$, while we examined that on the powders calcined between 600 and $800{ }^{\circ} \mathrm{C}$. This transformation may be caused by the formation of rutile nuclei on the surface of anatase particles followed by the growth of rutile toward the interior. ${ }^{29}$ The formation of rutile nuclei can be accelerated as the grain size becomes smaller. ${ }^{30}$

Figure 7 shows the evolution of anatase crystal size with calcination temperature for titania powders made at various $\mathrm{H}_{2} \mathrm{O}$ /TTIP molar ratios. Between 500 and $600{ }^{\circ} \mathrm{C}$ there is a steep increase of anatase crystal size for all powders regardless of initial $\mathrm{H}_{2} \mathrm{O}$ /TTIP ratio. Kumar et $a .^{31}$ reported that sol-gel made titania showed rapid growth of anatase crystals during the anatase to rutile phase transformation. It is apparent that the grain size of anatase crystals decreases with increasing initial $\mathrm{H}_{2} \mathrm{O}$ / TTIP molar ratio from 5 to 200 , but it shows a little increase for the initial $\mathrm{H}_{2} \mathrm{O}$ /TTIP molar ratio of 1000 for a constant calcination temperature. According to Ding et al., ${ }^{30}$ the number of nucleation sites increased with

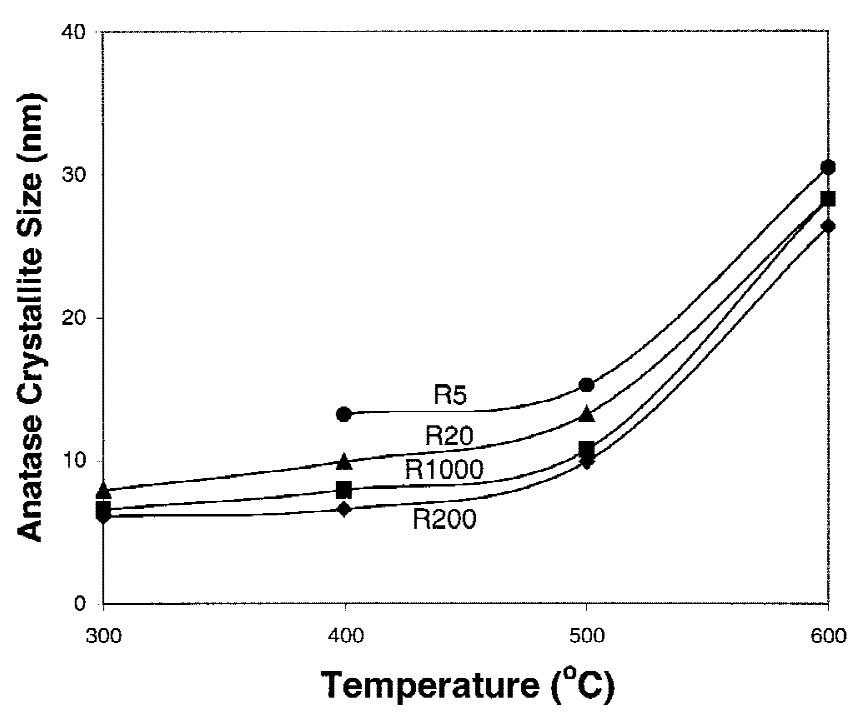

FIG. 7. Average crystallite size of anatase in the R5, R20, R200, and R1000 powders as a function of calcination temperature.

decreasing grain size, because the surface area, and consequently the transformation rate, were increased. On the basis of this result, it is possible to explain that the rutile content increased for the initial $\mathrm{H}_{2} \mathrm{O}$ /TTIP molar ratios from 5 to 200 due to the decrease of grain size in anatase crystals, but for the initial ratio of 1000 , it decreased again as the grain size increased with increasing water concentration.

\section{Specific surface area and porosity}

Figure 8 shows the specific surface areas of the powders made at different initial $\mathrm{H}_{2} \mathrm{O}$ /TTIP molar ratios as a function of calcination temperature. All powders show a decrease of the specific surface area with increasing calcination temperature due to the phase transformation and crystallite growth. It is interesting to observe that the R5 and R20 powders show higher surface areas than the R200 and R1000 powders at $150{ }^{\circ} \mathrm{C}$ but exhibit smaller surface areas at $600{ }^{\circ} \mathrm{C}$. This can be explained by the XRD and TG-DTA analyses as follows: At $150^{\circ} \mathrm{C}$, the R200 and R1000 powders had anatase phases, as confirmed by XRD analysis in Figs. 5(c) and 5(d), and thus, the particle sizes of the powders are bigger than those of the R5 and R20 powders which showed amorphous $\mathrm{Ti}(\mathrm{OH})_{4}$ by FTIRS and XRD. Hence, the specific surface areas of the R200 and R1000 powders are smaller than those of the R5 and R20 powders. However, the R5 and R20 powders go through the phase transformation of amorphous to anatase due to the removal of residual organics between 300 and $400{ }^{\circ} \mathrm{C}$ and between 150 and $300{ }^{\circ} \mathrm{C}$, respectively, as confirmed by TG-DTA, FTIRS, and XRD analyses in Figs. 1-3 and 5. This results in a rapid reduction of the specific surface areas of the R5 and R20 powders. Thus, at calcination temperatures above 
$400{ }^{\circ} \mathrm{C}$, the specific surface areas of the R5 and R20 powders become smaller than those of the R200 and R1000 powders.

Figure 9 shows the adsorption isotherms of the powders dried at $150{ }^{\circ} \mathrm{C}$ and made at various $\mathrm{H}_{2} \mathrm{O} / \mathrm{TTIP}$ molar ratios. The isotherm of the $\mathrm{R} 5$ powder is a combination of types I and IV (BDDT classification) ${ }^{32,33}$ with two very distinct regions: At low relative pressures, the isotherm exhibits high adsorption, indicating that the powder contains micropores (type I). However, at high

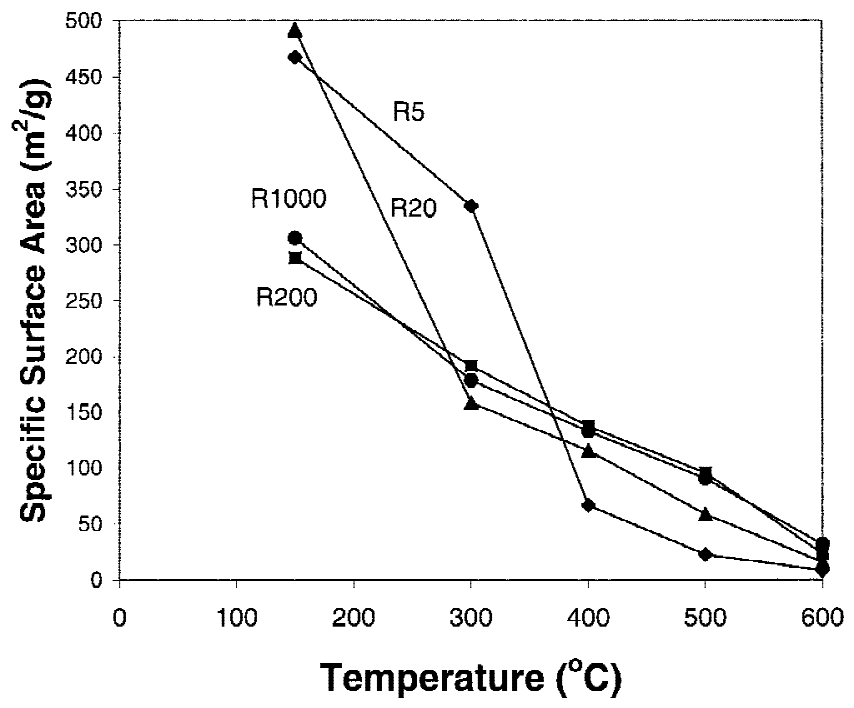

FIG. 8. The specific surface area of the R5, R20, R200, and R1000 powders as a function of calcination temperature.

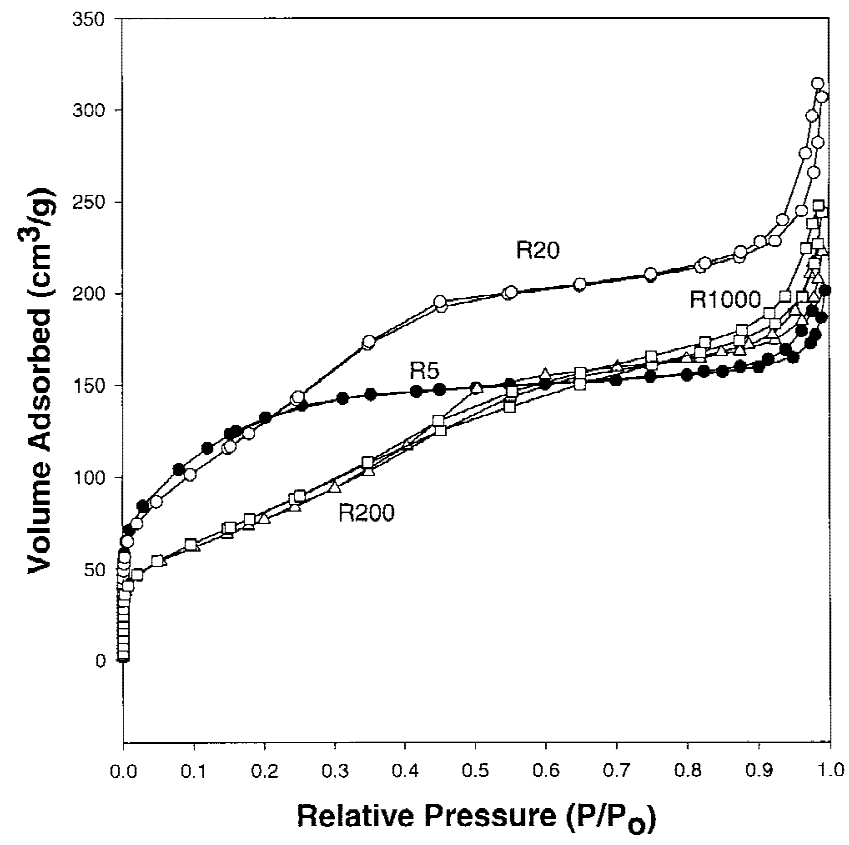

FIG. 9. Nitrogen adsorption isotherms obtained from the powders made at different initial $\mathrm{H}_{2} \mathrm{O}$ /TTIP molar ratios and dried at $150{ }^{\circ} \mathrm{C}$. relative pressures between 0.8 and 1.0, the curve exhibits a hysteresis loop indicating the presence of mesopores (type IV). The shape of the hysteresis loop is of a type $\mathrm{H} 3$, associated with narrow slitlike pores. On the other hand, the other powders (R20, R200, and R1000) have isotherms of type IV which exhibit hysteresis loops mostly of type H3. Thus, the powders are mesoporous and the pores have narrow slitlike shapes. Unlike the isotherm of the R5 powder with one hysteresis loop, the isotherms of the other powders have two hysteresis loops, indicating bimodal pore-size distributions in the mesoporous region.

Figure 10 shows the pore-size distributions of the powders prepared at various initial $\mathrm{H}_{2} \mathrm{O}$ /TTIP molar ratios and dried at $150{ }^{\circ} \mathrm{C}$. All powders show bimodal pore-size distributions consisting of intraaggregated pores with maximum pore diameters from micropores to $3.3 \mathrm{~nm}$ and interaggregated pores with maximum pore diameters of ca. $60 \mathrm{~nm}$. According to Kumar et al., ${ }^{34}$ the bimodal pore-size distributions arose from the hard aggregates in the powders. In addition, they reported that there are two types of pores present in the bimodal poresize distributions. One is fine intraaggregated pores (represented by the hysteresis loop in the lower $P / P_{0}$ range), and the other is larger interaggregated pores (hysteresis loop in the higher $P / P_{0}$ range). In Fig. 10, the maximum pore volume of the intraaggregated pores of the R5 powder lies in the microporous region (pore diameter less than $2 \mathrm{~nm}$ ). With increasing of the initial $\mathrm{H}_{2} \mathrm{O} / \mathrm{TTIP}$ mo-

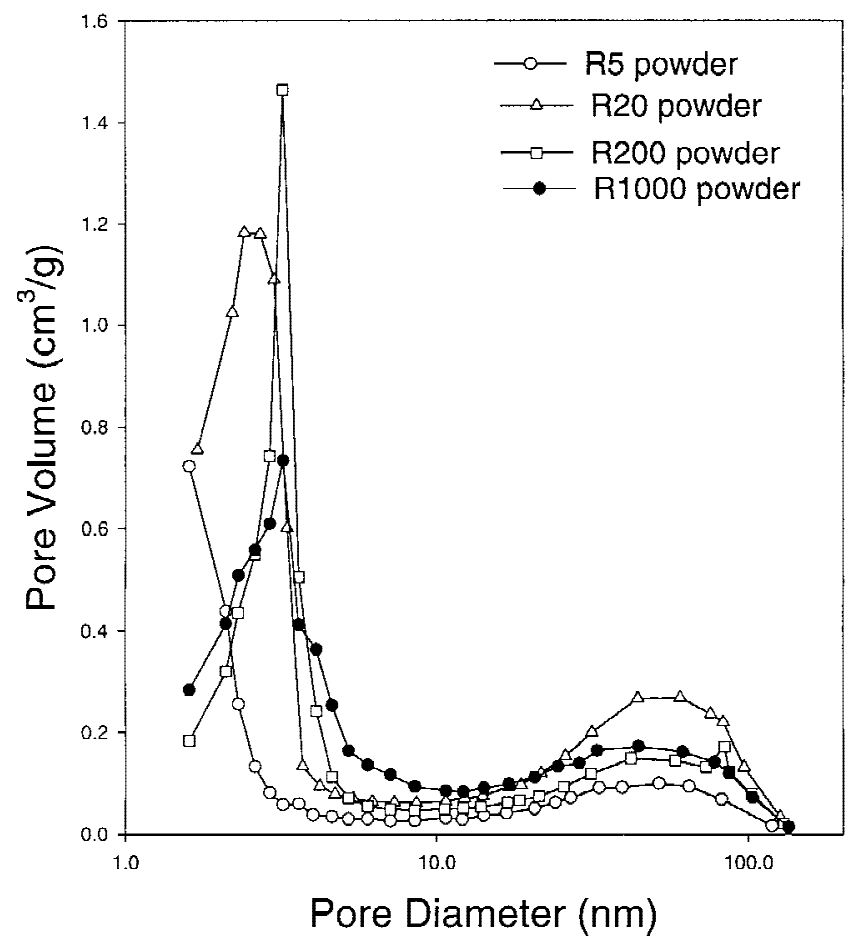

FIG. 10. Pore-size distribution curves of the powders dried at $150{ }^{\circ} \mathrm{C}$ after being made at different initial $\mathrm{H}_{2} \mathrm{O}$ /TTIP molar ratios. 
lar ratio, the maximum pore size of the intraaggregated pores shifts into the mesoporous region. However, the maximum pore sizes of the intraaggregated pores in the R200 and R1000 powders do not exhibit significant change compared to those of the R5 and R20 powders. Apparently, for the R5 powder, the particles within the aggregates tend to be packed more closely compared to
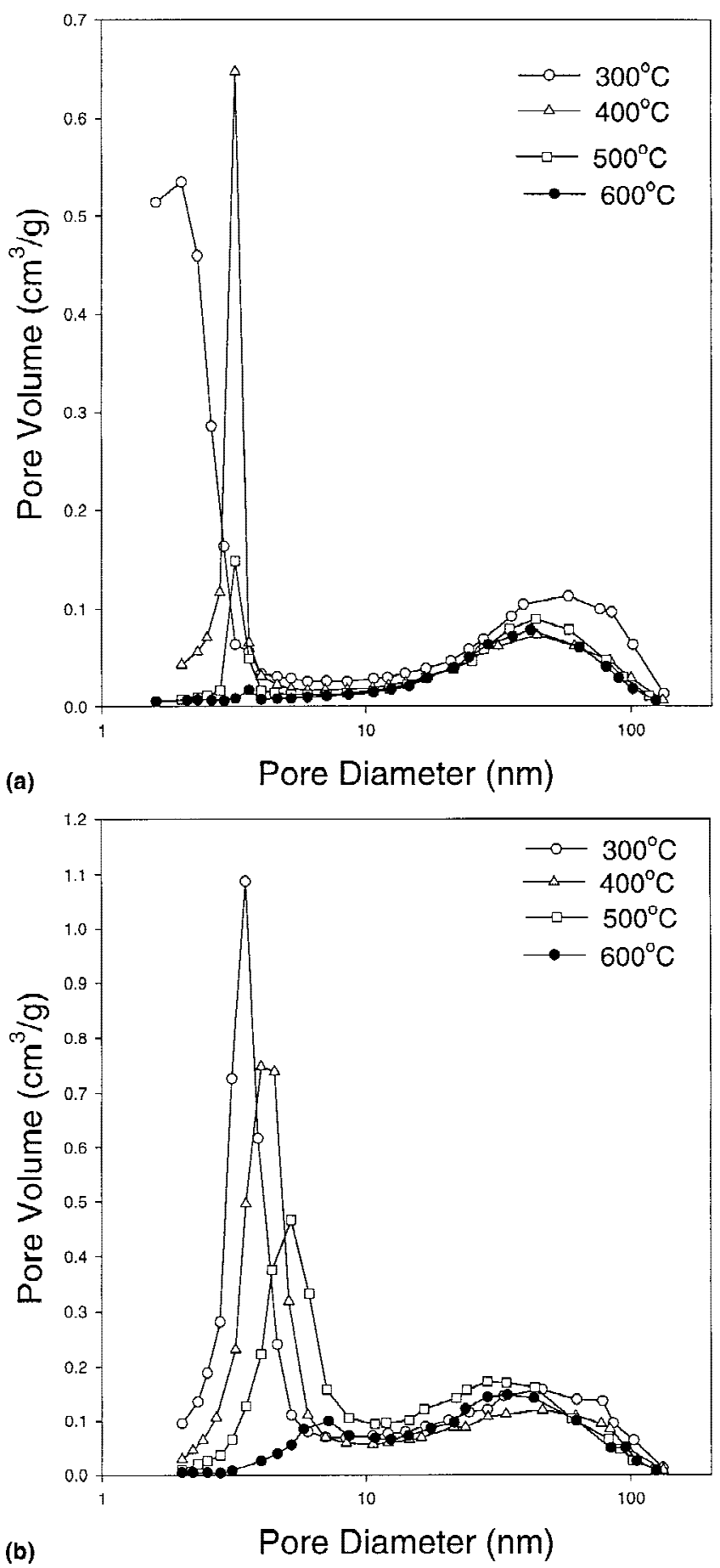

FIG. 11. Pore-size distribution curves of the (a) R5 and (b) R200 powders calcined at several temperatures. those of the other powders and the interstitial voids of the packed primary particles within the aggregates increase with increasing initial $\mathrm{H}_{2} \mathrm{O}$ /TTIP ratio.

Figures 11(a) and 11(b) show the pore size distributions of the R5 and R200 powders, respectively, calcined at several temperatures. For the R5 powder, the pores show bimodal distributions consisting of the intraaggregated and interaggregated pores from 300 to $500{ }^{\circ} \mathrm{C}$. At $600{ }^{\circ} \mathrm{C}$, the pores exhibit monomodal distribution of the interaggregated pores due to the collapse of the intraaggregated pores. The maximum pore volume of the intraaggregated pores in the powder calcined at $300{ }^{\circ} \mathrm{C}$ lies in the microporous region. However, when the powder is calcined at 400 and $500{ }^{\circ} \mathrm{C}$, the maximum pore size of the intraaggregated pores shifts into mesoporous region (ca. $3.3 \mathrm{~nm}$ ) indicating the growth of pores. This is caused by the formation of anatase crystallites and the removal of organic components remaining in the powder between 300 and $400{ }^{\circ} \mathrm{C}$. The formation of anatase crystallites results in the enlargement of maximum pore size in the intraaggregated pores from micropores to mesopores. The bimodal pore size distributions are also observed in the R200 powders calcined at several temperatures in Fig. 11(b). Contrary to the R5 powder, all maximum pore volumes of the intraaggregated pores of the R200 powder lie in the mesoporous region. It is also seen that the maximum pore size of the intraaggregated pores increases with increasing calcination temperature suggesting the growth of pores. It is interesting to note

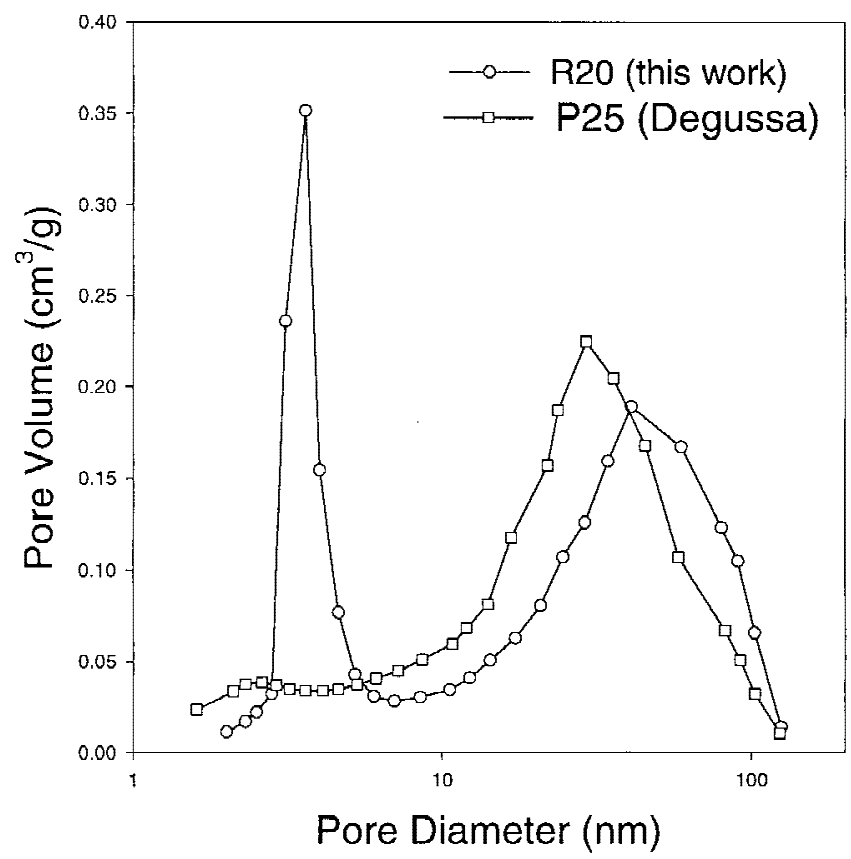

FIG. 12. Comparisons of the pore-size distribution curves of the R20 powder calcined at $500{ }^{\circ} \mathrm{C}$ and Degussa's P25 powder. 
that the intraaggregated pores in the R200 powder have not disappeared completely at $600{ }^{\circ} \mathrm{C}$, compared to those in the R5 powder.

Figure 12 shows the pore-size distributions of the R20 powder calcined at $500{ }^{\circ} \mathrm{C}$ and Degussa's P25 titania powder by flame hydrolysis of $\mathrm{TiCl}_{4}$. The P25 powder has similar specific surface area $\left(51.2 \mathrm{~m}^{2} / \mathrm{g}\right)$ with the R20 powder $\left(58.7 \mathrm{~m}^{2} / \mathrm{g}\right)$ but shows a totally different pore size distribution. The pore structure of the P25 powder is monomodal with a maximum for the pore diameter at $31 \mathrm{~nm}$. However, the pore size distribution of the R20 powder shows two maximum values at 3.8 and $50 \mathrm{~nm}$.

\section{CONCLUSIONS}

The water concentration during hydrolysis of TTIP plays an important role on the phase and pore structure of product titania powders. When the initial water concentration was small, the powder dried at $150{ }^{\circ} \mathrm{C}$ was amorphous $\mathrm{Ti}(\mathrm{OH})_{4}$ as residual organic components prevented the crystallization to anatase phase. However, when the initial water concentration was large, the powders dried at $150{ }^{\circ} \mathrm{C}$ were anatase. The phase transformation temperature of anatase to rutile was independent of the initial $\mathrm{H}_{2} \mathrm{O}$ /TTIP molar ratio.

All powders dried at $150{ }^{\circ} \mathrm{C}$ after being prepared with different $\mathrm{H}_{2} \mathrm{O}$ /TTIP molar ratios resulted in bimodal pore size distributions consisting of fine intraaggregated and larger interaggregated pores. The maximum size of the intraaggregated pores in the $\mathrm{R} 5$ powder prepared with a low water concentration $\left(\mathrm{H}_{2} \mathrm{O} / \mathrm{TTIP}=5\right)$ lied in the microporous region. With increasing water concentration, the maximum size of the intraaggregated pores shifted into the mesoporous region.

The R200 and R1000 powders prepared at high water concentrations $\left(\mathrm{H}_{2} \mathrm{O} / \mathrm{TTIP}=200\right.$ and 1000 , respectively) showed a gradual decrease of the surface areas with increasing calcination temperature. However, the R5 and R20 powders prepared at low water concentrations $\left(\mathrm{H}_{2} \mathrm{O} /\right.$ TTIP $=5$ and 20 , respectively) exhibited the rapid decrease of the specific surface areas between 300 and $400{ }^{\circ} \mathrm{C}$ and between 150 and $300{ }^{\circ} \mathrm{C}$, respectively, due to the phase transformation of amorphous to anatase. This resulted in higher surface areas of the R200 and R1000 powders than those of the R5 and R20 powders at $600{ }^{\circ} \mathrm{C}$.

\section{ACKNOWLEDGMENTS}

This research was sponsored in part by the SNF (Swiss National Science Foundation) and the KOSEF (Korea Science and Engineering Foundation).

\section{REFERENCES}

1. E.J. Mezey, Vapor Deposition (Wiley, New York, 1966), p. 423.

2. E.A. Barringer and H.K. Bowen, Langmuir 1, 414 (1985).

3. M.K. Akhtar, S.E. Pratsinis, and S.V.R. Mastrangelo, J. Am. Ceram. Soc. 75, 3408 (1992).

4. G.P. Fotou, S. Vemury, and S.E. Pratsinis, Chem. Eng. Sci. 49, 4939 (1994).

5. B. O'Regan and M. Graetzel, Nature 353, 737 (1991).

6. U. Gesenhues and T. Rentschler, J. Solid State Chem. 143, 210 (1999).

7. A. Kato, Y. Takeshima, and Y. Katatae, in Processing Science of Advanced Ceramics, edited by I.A. Aksay, G.L. McVay, and D.R. Ulrich (Mater. Res. Soc. Symp. Proc. 155, Pittsburgh, PA, 1989), p. 13.

8. S.E. Pratsinis, W. Zhu, and S. Vemury, Powder Technol. 86, 87 (1996).

9. F. Kirkbir and H. Komiyama, Chem. Lett. 5, 791 (1988).

10. K. Morishige, F. Kanno, S. Ogawara, and S. Sasaki, J. Phys. Chem. 89, 4404 (1985).

11. J.H. Jean and T.A. Ring, Langmuir 2, 251 (1986).

12. G.W. Koebrugge, L. Winnubst, and A.J. Burggraaf, J. Mater. Chem. 3, 1095 (1993).

13. M. Kallala, C. Sanchez, and B. Cabrane, Phys. Rev. E 48, 3692 (1993).

14. B.E. Yoldas, J. Mater. Sci. 21, 1087 (1986).

15. X.Z. Ding, Z.Z. Qi, and Y.Z. He, J. Mater. Sci. Lett. 14, 21 (1995).

16. T. Sasamoto, S. Enomoto, Z. Shimoda, and Y. Saeki, J. Ceram. Soc. Jpn. 101, 226 (1993).

17. K. Kato, Chem. Soc. Jpn. 65, 34 (1992).

18. S. Sato, S. Oimatsu, R. Takahashi, T. Sodesawa, and F. Nozaki, Chem. Commun. 22, 2219 (1997).

19. C.J. Brinker and G.W. Scherer, Sol-Gel Science (Academic Press, San Diego, CA, 1990).

20. M.F. Yan and W.W. Rhodes, Mater. Sci. Eng. 61, 59 (1983).

21. R.A. Spurr and H. Myers, Anal. Chem. 29, 760 (1957).

22. B.D. Cullity, Elements of X-ray Diffraction (Addison-Wesley, Reading, MA, 1978).

23. K.S.W. Sing, D.H. Everett, R.A.W. Haul, L. Moscou, R.A. Pierotti, J. Rouquerol, and T. Siemieniewska, Pure Appl. Chem. 57, 603 (1985).

24. I.A. Montoya, T. Viveros, J.M. Dominguez, L.A. Canales, and I. Schifter, Catal. Lett. 15, 207 (1992).

25. J. Rubio, J.L. Oteo, M. Villegas, and P. Duran, J. Mater. Sci. 32, 643 (1997).

26. T. Lopez, E. Sanchez, P. Bosch, Y. Meas, and R. Gomez, Mater. Chem. Phys. 32, 141 (1992).

27. V.C. Farmer, Infrared Spectra of Minerals (Mineralogical Society, London, United Kingdom, 1974).

28. K. Terabe, K. Kato, H. Miyazaki, S. Yamaguchi, A. Imai, and Y. Iguchi, J. Mater. Sci. 29, 1617 (1994).

29. H.D. Jang, AIChE J. 43, 2704 (1997).

30. X.Z. Ding, X.H. Liu, and Y.Z. He, J. Mater. Sci. Lett. 15, 1789 (1996).

31. K-N.P. Kumar, K. Keizer, and A.J. Burggraaf, J. Mater. Chem. 3, 1141 (1993).

32. K.S.W. Sing, D.H. Everett, R.A.W. Haul, L. Moscou, R.A. Pierotti, J. Rouquerol, and T. Siemieniewska, Pure Appl. Chem. 57, 603 (1985).

33. S.J. Gregg and K.S.W. Sing, Adsorption, Surface Area and Porosity (Academic Press, London, United Kingdom, 1982).

34. K-N.P. Kumar, J. Kumar, and K. Keizer, J. Am. Ceram. Soc. 77, 1396 (1994). 